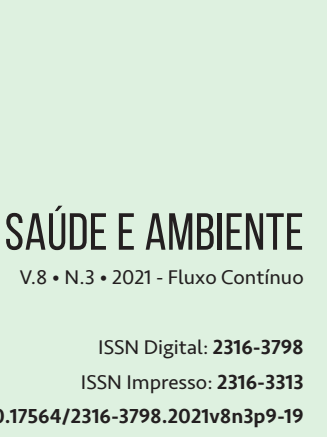

DOI: $10.17564 / 2316-3798.2021 v 8 n 3 p 9-19$

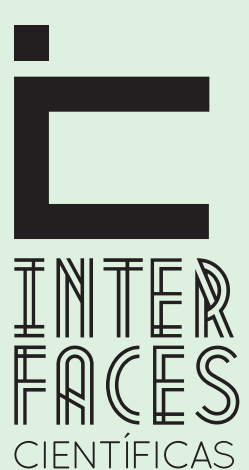

\section{CORONAVÍRUS: MEDIDAS PREVENTIVAS DOS TRABALHADORES DO HOSPITAL UNIVERSITÁRIO DO SERGIPE}

CORONAVIRUS: PREVENTIVE MEASURES FOR WORKERS AT HOSPITAL UNIVERSITÁRIO DO SERGIPE

CORONAVIRUS: MEDIDAS PREVENTIVAS PARA LOS TRABAJADORES DEL HOSPITAL UNIVERSITÁRIO DO SERGIPE
Ellen Dionélia Alencar Rodrigues Rosa ${ }^{1}$ Tereza Raquel Ribeiro de Sena ${ }^{2}$ Regiane Cristina do $\mathrm{Amaral}^{3}$

\section{RESUMO}

No Brasil o primeiro caso de COVID-19 surgiu no dia 26 de fevereiro de 2020 e a partir deste fato novos casos foram surgindo em diferentes regiões do país. Os governantes juntamente com o Ministério da Saúde e Organização Mundial de Saúde, criaram medidas para conter a epidemia. Entre tais medidas têm-se atitudes preventivas como distanciamento social, uso de álcool em gel nas mãos, uso de máscara facial, entre outros. Assim o objetivo do presente estudo foi verificar quais medidas de promoção e prevenção a COVID-19 estão sendo adotadas pelos trabalhadores do Hospital Universitário de Sergipe (HU) - Aracaju e se elas estão de acordo com o Ministério da Saúde. Pesquisa descritiva do tipo transversal no qual foi aplicado um questionário on-line (Google Forms) aos funcionários do HU sobre quais medidas preventivas estão sendo utilizadas pelos profissionais. Foram respondidos 60 questionários, sendo $18 \%$ compostos por profissionais técnicos em enfermagem. $45,8 \%$ com idade de 31 a 40 anos, $65 \%$ utilizam carro como meio de transporte, $65 \%$ sexo feminino. Sobre os meios de proteção contra o COVID-19 no trabalho, 83,3\% utilizam álcool em gel, $70 \%$ nas mãos, $76,7 \%$ utilizam máscara descartável e $56,7 \%$ utilizam distanciamento social. Sobre os meios de proteção em casa, 89,9\% lavam as mãos com água e sabão, $69,5 \%$ tomam banho ao chegar em casa e $66 \%$ deixam o sapato fora de casa. Sobre troca de máscara no local do trabalho, 38\% trocam 2 vezes por dia. As medidas de proteção recomendadas pelo Ministério da Saúde estão sendo utilizadas pela maioria dos trabalhadores.

\section{PALAVRAS-CHAVE}

Infecções por Coronavírus. Odontologia. Biossegurança. 


\section{ABSTRACT}

In Brazil, the first case of COVID 19 emerged on February 26, 2020 and from this fact new cases appeared in different regions of the country. The government, together with the Ministry of Health and the World Health Organization, created measures to contain the epidemic. Among such measures, there are preventive attitudes such as social distance, use of alcohol gel in the hands, use of a facemask, among others. Thus, the objective of the present study was to verify which measures to promote and prevent COVID 19 are being adopted by workers at the Hospital Universitário de Sergipe - Aracaju (HU) and whether these are in agreement with the Ministry of Health. Descriptive cross-sectional survey in which an online questionnaire (Google Forms) was applied to HU employees on what preventive measures are being used by professionals. 60 questionnaires were answered, $18 \%$ of which were composed by nursing technicians. $45.8 \%$ aged 31 to 40 years, $65 \%$ use a car as a means of transport, $65 \%$ female. Regarding the means of protection against COVID 19 at work, $83.3 \%$ use alcohol gel $70 \%$ on their hands, $76.7 \%$ use a disposable mask and $56.7 \%$ use social distance. Regarding the means of protection at home, $89.9 \%$ wash their hands with soap and water, $69.5 \%$ bathe when they get home and $66 \%$ leave their shoes outside. Regarding mask changes at the workplace, $38 \%$ change twice a day. Most workers are using the protective measures recommended by the Ministry of Health.

\section{KEYWORDS}

Coronavirus Infections. Dentistry. Biosafety

\section{RESUMEN}

En Brasil, el primer caso de COVID-19 surgió el 26 de febrero de 2020 y de este hecho aparecieron nuevos casos en diferentes regiones del país. El gobierno, junto con el Ministerio de Salud y la Organización Mundial de la Salud, creó medidas para contener la epidemia. Entre tales medidas se encuentran actitudes preventivas como el distanciamiento social, el uso de alcohol en gel en las manos, el uso de mascarilla, entre otras. Así, el objetivo del presente estudio fue verificar qué medidas de promoción y prevención de COVID-19 están adoptando los trabajadores del Hospital Universitário de Sergipe - Aracaju (HU) y si están de acuerdo con el Ministerio de Salud. Un estudio descriptivo transversal en el que se aplicó un cuestionario en línea (Google Forms) a los empleados de HU sobre qué medidas preventivas están utilizando los profesionales. Se contestaron 60 cuestionarios, el 18\% de los cuales fueron compuestos por técnicos de enfermería. El 45,8\% de 31 a 40 años, el 65\% utiliza el coche como medio de transporte, el $65 \%$ mujeres. En cuanto a los medios de protección frente al COVID-19 en el trabajo, el 83,3\% utiliza alcohol en gel $70 \%$ en las manos, el 76,7\% utiliza mascarilla 
desechable y el $56,7 \%$ utiliza distanciamiento social. En cuanto a los medios de protección en el hogar, el $89,9 \%$ se lava las manos con agua y jabón, el 69,5\% se baña al llegar a casa y el 66\% deja los zapatos fuera. En cuanto a los cambios de mascarilla en el lugar de trabajo, el 38\% cambia dos veces al día. La mayoría de los trabajadores utilizan las medidas de protección recomendadas por el Ministerio de Salud.

\section{PALABRAS CLAVE}

Infecciones por coronavirus, Odontología, Bioseguridad

\section{INTRODUÇ̃̃̃O}

A epidemia do coronavírus (COVID-19), originária de Wuhan, China, tornou-se um grande desafio à saúde pública por ter se espalhado pelo mundo, atingindo mais de 76 milhões de casos confirmados e cerca de 1.643.339 mortes até dezembro de 2020 (OMS, 2020). Seu contágio acontece por gotículas por via área de pessoas contaminadas, toque de mão, gotículas de saliva, espirro, tosse, catarro e objetos ou superfícies contaminadas (BRASIL, 2020), tendo período de incubação de 5 a 6 dias em média (BACKER et al., 2020; LI et al., 2020; MENG et al., 2020). Entre os sintomas tem-se febre e tosse seca, falta de ar, fadiga e outros sintomas atípicos, como dor muscular, confusão, dor de cabeça, dor de garganta, diarreia e vômito (CHEN; ZHOU et al., 2020; GUAN et al., 2020). Alguns casos desenvolvendo complicações agudas severas.

Estudos recentes definem como grupos de risco para o agravamento do COVID-19 os portadores de doenças crônicas, acima de 60 anos, gestantes, puérperas e crianças menores de 5 anos. Dentro das enfermidades ligadas à maior mortalidade pela doença tem-se: diabetes, hipertensão, asma, doença pulmonar obstrutiva crônica, doenças hematológicas, doenças imunodepressoras, obesidade (BRASIL, 2020). Além dos citados, também são considerados grupos de risco a população indígena, carcerária, residentes em instituições de longa permanência para idosos e fumantes (MATO GROSSO DO SUL, 2020).

No Brasil, o primeiro caso surgiu no dia 26 de fevereiro de 2020 e a partir deste fato novos casos foram surgindo em diferentes regiões do país, em dezembro de 2020 já somam mais de 7 milhões de casos e mais de 180 mil óbitos no Brasil (OMS, 2020). Assim o Ministério da Saúde e Organização Mundial de Saúde (BRASIL, 2020), criaram medidas para conter a epidemia, entre tais medidas tem-se os isolamentos de cidades, uso obrigatório de máscaras em locais públicos, fechamento de comércio não considerado essencial, uso de máscaras, álcool em gel para limpeza das mãos entre outros (BRASIL, 2020).

Os hospitais são locais nos quais o paciente com sintomas mais graves da doença, ou seja, com carga viral da COVID-19, procura por assistência médica, desta forma os trabalhadores destes estabelecimentos estariam mais expostos ao vírus, podendo inclusive levá-lo para os familiares ou pessoas que transladam com eles em transportes públicos, entre outros. Segundo a Organização Pan-Ameri- 
cana de Saúde (OPAS, 2020) mais de 570 mil profissionais da saúde se contaminaram com o vírus e destes 2,5 mil vieram a óbitos somente nas américas. Nos EUA e México os trabalhadores da saúde representam um em cada sete casos da doença (OPAS, 2020).

É imprescindível, tendo em vista a maior carga viral nos hospitais e a maior incidência nos profissionais da saúde, conhecer as condutas de prevenção à COVID-19 empregadas por estes profissionais. Assim o objetivo do presente estudo foi verificar quais medidas de promoção e prevenção à COVID-19 estão sendo adotadas pelos profissionais que trabalham no HU de Sergipe e se estas estão de acordo com o Ministério da Saúde.

\section{MÉTODO}

Este projeto foi aprovado pelo comitê de ética em pesquisa da Universidade Federal de Sergipe (CAAE: 35869120.2.0000.5546), foi realizado após o participante visualizar o Termo de Consentimento Livre e Esclarecido e aceitar participar do estudo.

Trata-se de um estudo descritivo do tipo transversal realizado com os profissionais que trabalham no Hospital Universitário de Sergipe (HU), localizado em Aracaju - Sergipe. Foi aplicado um questionário (via Google Forms) nos meses de outubro e novembro de 2020 aos funcionários que trabalham no HU, nas diversas profissões, entre elas, dentistas, médicos, enfermeiros, auxiliares ou técnicos em enfermagem, fonoaudiólogos entre outros. Do total de e-mails enviados pela plataforma de Administração Interna de Comunicação do HU, 60 voluntários responderam ao questionário.

O questionário continha 14 perguntas que envolviam idade, tipo de função, se está trabalhando no ambiente do Hospital Universitário de Sergipe no período da quarentena, se teve ou tem contato com pessoas que tiveram COVID 19 no ambiente de trabalho, se teve ou tem contato com pessoas que tiveram COVID 19 em casa, anos de profissão, meio de transporte que utiliza para ir ao trabalho, medidas que utiliza preventivamente para o COVID 19 em casa, medidas que utiliza preventivamente para o COVID 19 no trabalho.

Os dados foram analisados de forma descritiva, utilizando a ferramenta Microsoft Excel.

\section{RESULTADOS}

Responderam ao questionário 60 funcionários, sendo $65 \%$ do sexo feminino, $18,3 \%$ compostos por técnicos de enfermagem, 16,6\% Cirurgião dentista, 10\% Enfermeiros, 45,8\% com idade entre 31 a 40 anos, $39 \%$ utilizam o próprio carro como meio de transporte, $15 \%$ utiliza transporte por aplicativo e $15 \%$ transporte coletivo e $80 \%$ moram entre duas a quatro pessoas na residência.

Ao se questionar como o trabalhador se protege contra a COVID-19 no trabalho, verifica-se que a maioria usa álcool em gel e máscara descartável (Figura 1). 
Figura 1 - Métodos utilizados pelos trabalhadores do HU Sergipe para se protegerem no trabalho contra o COVID 19. Hospital Universitário - Aracaju/SE, 2020

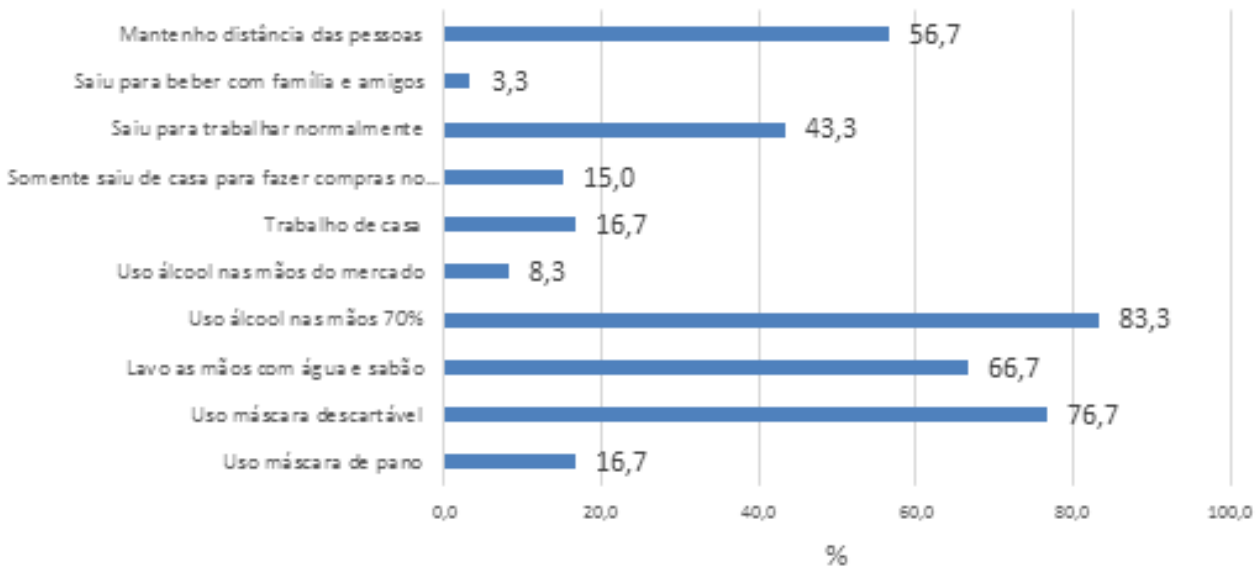

Fonte: Dados da pesquisa.

Ao se verificar como o trabalhador se protege contra a COVID-19 em sua casa, verifica-se que a maioria lava as mãos com água e sabão, também lava as mãos e toma banho ao chegar em casa (Figura 2).

Figura 2 - Métodos utilizados pelos trabalhadores do HU Sergipe para se protegerem em casa contra o COVID 19. Hospital Universitário - Aracaju/SE, 2020

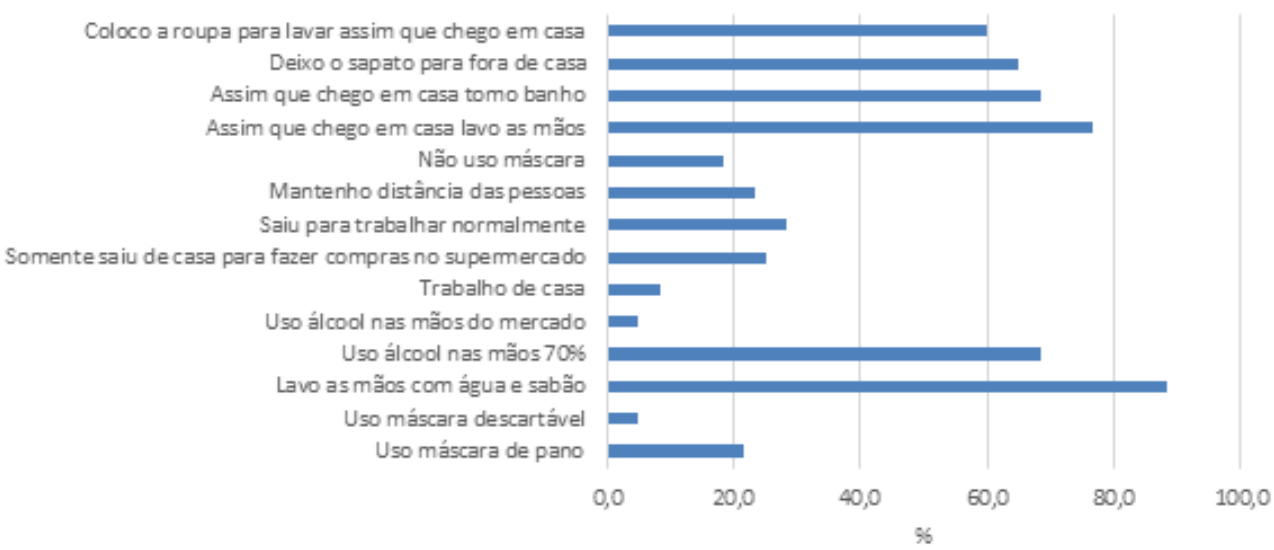

Fonte: Dados da pesquisa.

Quando questionados sobre o uso de transporte coletivo em geral, 79,7\% afirmou utilizar o serviço e $80 \%$ deles fazem uso de máscara e álcool nas mãos como medida de prevenção à COVID-19 nesses ambientes. A maioria afirmou ainda tomar banho e colocar a roupa para lavar ao chegar em casa (Figura 3). 
Figura 3 - Cuidados utilizados pelos trabalhadores do HU Sergipe para se protegerem no transporte público contra o COVID 19. Hospital Universitário - Aracaju/SE, 2020

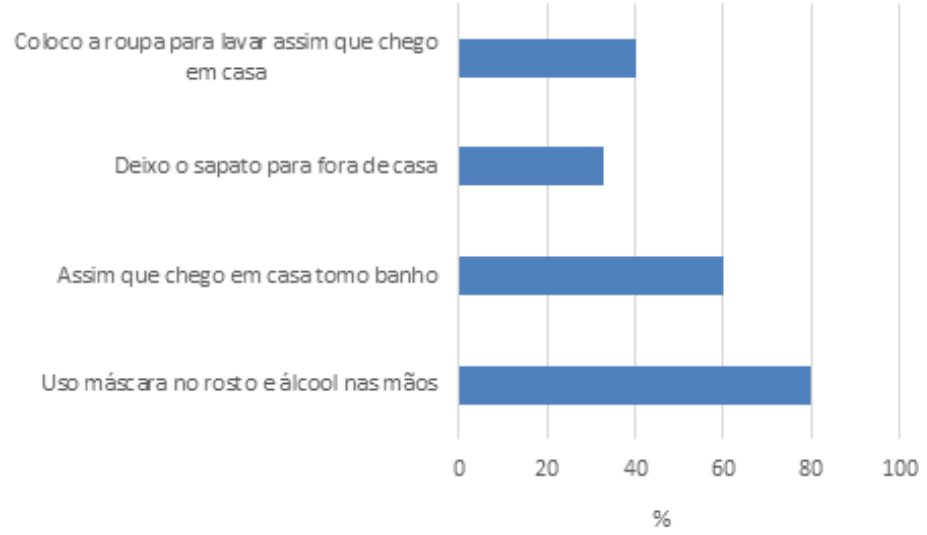

Fonte: Dados da pesquisa

Em relação aos locais públicos, $66,1 \%$ usa máscara de pano ao circular por estes ambientes. Nos dias de folga os trabalhadores afirmaram ir ao supermercado (65,5\%), casa dos familiares $(55,2 \%)$, praia $(24,1 \%)$, bares e restaurantes (8,9), além de farmácia $(1,7 \%)$ e assistência médica $(1,7 \%)$. Ao ser questionado sobre quantas vezes a máscara é trocada no trabalhado, 55,2\% afirmaram trocar duas vezes ao dia e $27,5 \%$ alegou trocar apenas uma vez.

\section{DISCUSSÃO}

A literatura caracteriza como grupos de risco para o agravamento da COVID-19 os portadores de doenças crônicas, acima de 60 anos, gestantes, puérperas e crianças menores de 5 anos (BRASIL, 2020; DIAS et al., 2020). Foi observado que $57,7 \%$ dos profissionais da amostra possuem entre $18-40$ anos e cerca de $18,6 \%$ têm 51 ou mais anos de idade, sendo esses considerados de maior risco para intensificação quadro da doença.

Os profissionais da saúde estão expostos diretamente aos pacientes infectados, por isto recebem uma alta carga viral e devido a este alto risco de contaminação com a doença estes profissionais são orientados a se isolarem da família, para evitar se transformar em uma via de transmissão para seus familiares, muitas vezes pertencentes ao grupo de risco e outras pessoas (BRASIL, 2020; TEIXEIRA et al., 2020). Em nossa amostra foi verificado que $80 \%$ dos profissionais residem com duas a quatro pessoas e $11,7 \%$ moram com mais de quatro familiares.

Além do isolamento domiciliar é preconizado pelos órgãos da saúde que preferivelmente estes profissionais utilizem transporte privado, para evitar o nível de disseminação do vírus devido ao alto risco 
de contaminação dentro dos hospitais. (BRASIL, 2020). 0 estudo demonstrou que $68,3 \%$ dos profissionais utilizam carro ou moto privados para irem ao trabalho, porém 15\% da amostra vão ao trabalho com transporte público e quando questionados sobre os cuidados ao utilizar esse serviço $80 \%$ destes utilizam máscaras, álcool à $70 \%$ nas mãos e ao chegar em casa tomam banho. Além disso, 40\% dos profissionais colocam a roupa para lavar assim que chegam em casa e deixam os sapatos fora de casa, seguindo corretamente as orientações previstas pelos órgãos de saúde, ministério da saúde e OMS.

O Ministério da Saúde recomenda a utilização de máscaras em todos os ambientes, ressaltando que as máscaras de tecido não são Equipamentos de Proteção Individual (EPI), mas podem funcionar como uma barreira física, em especial contra a saída de gotículas potencialmente contaminadas (BRASIL, 2020; OMS, 2020). Este estudo identificou que todos os profissionais da amostra alegam utilizar máscaras em ambiente público. Ademais quando questionados a forma de prevenção da COVID-19 no trabalho mais de 80\% utilizam álcool nas mãos, máscara descartável e lavam as mãos com água e sabão, relataram, também, manter distância das pessoas, como preconizado pelos órgãos vigentes em saúde.

Os cuidados com a COVID-19 em casa preconizados pelos órgãos de saúde são principalmente: tirar os sapatos ao entrar em casa, lavar todas as roupas que usou fora, higienizar as embalagens de compras, lavar as mãos com água e sabão, utilizar álcool nas mãos, assim como higienizar os eletrodomésticos (BRASIL, 2020; OMS, 2020; LUZ; NORONHA; NAVARRO, 2020). Os cuidados mais relatados na pesquisa foram: lavar as mãos com água e sabão, utilizar álcool nas mãos, lavar as roupas assim que chega da rua, além de tomar banho e lavar as mãos ao chegar da rua. No entanto, uma pequena porcentagem higieniza os sapatos e os eletrodomésticos, configurando-se assim uma lacuna na prevenção contra a COVID-19, uma vez que estes são potenciais portadores do vírus aumentando as chances de contaminação.

O Ministério da Saúde orienta a população em geral sair apenas para atividades essenciais e evitar a circulação desnecessária nas ruas, estádios, teatros, shoppings, shows, cinemas e igrejas (BRASIL, 2020). Os profissionais do HU quando questionados sobre saídas em seus dias de folga, relataram em sua maioria ir ao supermercado $(65,5 \%)$, casa dos familiares $(55,2 \%)$, praia $(24,1 \%)$, bares e restaurantes $(8,9)$, além de farmácia $(1,7 \%)$ e assistência médica $(1,7 \%)$. A alta incidência de saídas para além das orientações dos órgãos de saúde, se deve em parte à flexibilização do comércio por parte dos órgãos de estado. Vale ressaltar que para se resguardar e proteger os entes queridos a recomendação de todos os órgãos em saúde continua sendo o isolamento e limitação das atividades diárias de cunho não essencial.

A literatura, junto aos órgãos de saúde, indica a utilização de máscaras de tecido apenas por duas horas, depois desse período é necessário trocar, além disso deve-se trocar a máscara sempre que apresentar sujidades ou umidade e descartar a máscara sempre que apresentar sinais de deterioração ou funcionalidade comprometida (BRASIL, 2020; OMS, 2020). Os profissionais quando questionados sobre quantas vezes ao dia trocam suas máscaras, 55,17\% deles, afirmaram trocar 2 vezes ao dia e 27,5\% alegou trocar apenas 1 vez. Sendo dessa forma, quantidade insuficiente tendo, de acordo com o Ministério da Saúde, consequente perda da eficiência dessas máscaras, ficando assim o profissional desprotegido maior parte do dia. 


\section{CONCLUSÃO}

Após verificar as medidas de promoção e prevenção à COVID-19 adotadas pelos trabalhadores do Hospital Universitário de Sergipe e compará-las com as orientações dos órgãos de saúde, podemos concluir que na prática a maior parte das orientações estão sendo seguidas corretamente dentro da realidade de cada indivíduo.

\section{REFERÊNCIAS}

BRASIL. Ministério da Saúde. 0 que é COVID-19. Disponível em: https://coronavirus.saude.gov.br/ sobre-a-doenca\#o-que-e-covid. Acesso em: 28 jan 2021.

BRASIL. Organização Pan-Americana de Saúde. Folha informativa COVID-19: Escritório da OPAS e da OMS no Brasil. Atualizado em 25 de agosto 2020. Disponível em: https://www.paho.org/bra/index. php?option=com_content\&view=article\&id=6101: covid19\&ltemid=875\#risco. Acesso em: 04 fev 2021.

BRASIL. Ministério da Saúde. Secretaria de Vigilância em Saúde. Guia de Vigilância

Epidemiológica: Emergência de Saúde Pública de importância nacional pela doença pelo Coronavírus 2019: Vigilância de Síndromes Respiratórias Agudas: COVID-19. Brasília, DF, 5 de agosto de 2020. 58 p. Disponível em: https://portalarquivos.saude.gov.br/images/af_gvs_ coronavirus_6ago20_ajustes-finais-2.pdf. Acesso em: 28 jan 2021

BACKER, J. A.; KLINKENBERG, D.; WALLINGA, J. Incubation period of 2019 novel coronavirus (2019$\mathrm{nCoV}$ ) infections among travellers from Wuhan, China, 20-28 january 2020. Euro Surveill, v. 25, n. 5. DOI: 10.2807/1560-7917. 2020.ES.2020.25.5.2000062.

CHEN, N.; ZHOU, M.; DONG, X.; QU, J.; GONG, F.; HAN, Y.; QIU, Y.; WANG, J.; LIU, Y.; WEI, Y. et al. Epidemiological and clinical characteristics of 99 cases of 2019 novel coronavirus pneumonia in Wuhan, China: a descriptive study. Lancet, v. 395, n. 10223, p. 507-513, 2020.

CORONAVÍRUS: o que você precisa saber e como prevenir o contágio. Disponível em: https:// coronavirus.saude.gov.br/. Acesso em: 27 dez. 2020.

CAMPOS, Mônica Rodrigues et al. Burden of disease from COVID-19 and its acute and chronic complications: reflections on measurement (DALYs) and prospects for the Brazilian Unified National Health System. Cad saúde públ, v. 36, p. e00148920, 2020. 
DIAS, J. A. A. et al. Reflexões sobre distanciamento, isolamento social e quarentena como medidas preventivas da COVID-19. Rev Enferm Centro-Oeste Min, v. 10, 1 out. 2020.

GUAN, W. J.; NI, Z. Y.; HU, Y.; LIANG, W. H.; OU, C. Q.; HE, J. X.; LIU, L.; SHAN, H.; LEI, C. L.; HUI, D. S. et al. Clinical characteristics of 2019 novel coronavirus infection in China. medRxiv, 2020. DOI:10.1 101/2020.1102.1106.20020974

GU, J.; HAN, B.; WANG, J. COVID-19: gastrointestinal manifestations and potential fecal oral transmission. Gastroenterol, v. 158, n. 44, p. 1518-15199, 2020.

LI, Q.; GUAN, X.; WU, P.; WANG, X.; ZHOU, L.; TONG, Y.; REN, R.; LEUNG, K. S. M.; LAU, E. H. Y.; WONG, J. Y. et al. Early transmission dynamics in Wuhan, China, of novel coronavirus-infected pneumonia. $\mathbf{N}$ Engl J Med. [epub ahead of print], 29 jan. 2020. DOI:10.1056/NEJMoa2001316.

LUZ, A. R.; NORONHA, R. M. DE; NAVARRO, T. P. COVID-19: medidas de prevenção de lesão por pressão ocasionadas por equipamentos de proteção individual em profissionais da saúde. Rev Enferm Atual In Derme, v. 93, p. e-020011, 20 ago. 2020.

MATA, I.; GOES, A. R.; BIZARRA, M. F. Importância da higiene oral durante a pandemia: o caso das pessoas institucionalizadas. Maio de 2020. Disponível em: https://www.saudeoral.pt/destaques/ opiniaoimportancia-da-higiene-oral-durante-a-pandemia-o-caso-das-pessoas-institucionalizadas/. Acesso em: 28 jan 2021

MATO GROSSO DO SUL. Secretaria de Estado de Saúde. Vigilância em Saúde. Gerência Técnica de Influenza e Doenças Respiratórias. Nota Técnica Covid-19. Revisão 14. Campo Grande: SESMS. 2020:28p. Disponível em: https://www.saude.ms.gov.br/wp-content/uploads/2020/07/NotaT\%C3\%A9cnica-COVID-19-Revis\%C3\%A3o-14-31-07-2020.pdf. Acesso em: 04 fev 2021

OMS | Brasil. Disponível em: <https://www.who.int/eportuguese/countries/bra/pt/>. Acesso em: 27 dez. 2020.

TEIXEIRA, C. F. DE S. et al. A saúde dos profissionais de saúde no enfrentamento da pandemia de Covid-19. Ciên Saúde Col, v. 25, n. 9, p. 3465-3474, 28 set.2020.

WADMAN, M.; COUZIN-FRANKEL, J.; KAISER, J.; MA - TACIC, C. How does coronavirus kill? Clinicians trace a ferocious rampage through the body, from brain to toes. Science, 17 abr. 2020. Disponível em: https://www.sciencemag.org/news/2020/04/ how-does-coronavirus-kill-clinicianstraceferocious-rampage-through-body-brain-toes. Acesso em: 15 jan 2021 
WU, Y.; GUO, C.; TANG, L.; HONG, Z.; ZHOU, J.; DONG, X. et al. Prolonged presence of SARS-CoV-2 viral RNA in faecal samples. Lancet Gastroenterol Hepatol, v. 5, p. 434-435, 2020. 
1 Acadêmica do curso de Odontologia da Universidade Federal de Sergipe - UFS.

E-mail: ellenrodrigues.odonto@gmail.com

2Doutora; Professora do departamento de Fonoaudiologia da Universidade Federal do Sergipe - UFS.

E-mail: tr@trsena.com.br

3 Doutora; Professora do departamento de Odontologia e do programa de pós-graduação em Odontologia - PRODONTO da Universidade Federal de Sergipe - UFS.

E-mail: amaralre@yahoo.com.br

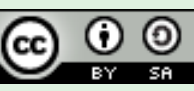

Este artigo é licenciado na modalidade acesso abertosob a Atribuição-Compartilhalgual CC BY-SA

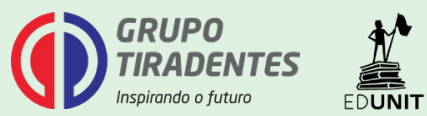

